\title{
ВЛИЯНИЕ БАЗЫ ДАННЫХ НА ОЦЕНКУ СЕЙСМИЧЕСКОГО ПОТЕНЦИАЛА СЛАБОАКТИВНЫХ РЕГИОНОВ
}

\author{
Т.С. Блинова \\ Горный институт УрО РАН, г. Пермь
}

\begin{abstract}
Аннотация: Составление карт сейсмического районирования слабоактивных регионов имеет очевидное научное и практическое значение. Это связано с эксплуатацией и строительством промышленных и гражданских объектов, опасных строений и сооружений. Основная трудность решения этой задачи состоит в невозможности использования стандартных методов и технологий. В Горном институте УрО РАН разработана методика сейсмического районирования слабоактивных регионов. Она основана на прогнозировании геодинамически неустойчивых зон с использованием геологических и геофизических данных и определении сейсмического потенциала региона. Эти зоны отличаются свойствами среды и динамикой процессов, которые стремятся к их дестабилизации под действием региональных и глобальных сил, и находят свое проявление в сейсмичности. Их модель является основой для построения прогнозных карт максимальных магнитуд возможных землетрясений. Рассмотрен процесс подготовки и построения прогнозных карт с помощью геоинформационной системы «ГЕО». Исследования проводились для Западно-Уральского и ТиманоСевероуральского регионов, восточной окраины Восточно-Европейской платформы и территории Соединенного Королевства Великобритании и Северной Ирландии. Накопленный опыт построения прогнозных карт максимальных магнитуд возможных землетрясений позволил обобщить геологические и геофизические данные различных вариантов прогноза. В результате получены общие и дополнительные параметры, необходимые для уменьшения ошибки аппроксимации таких карт для больших по площади и неоднородных по тектонике регионов. Определены параметры, которые вносят наиболее существенный вклад в прогноз. Достоверность прогнозных карт обоснована связью распределения сейсмического потенциала с тектоникой, геодинамикой и современной сейсмичностью регионов.
\end{abstract}

Ключевые слова: база данных, сейсмический потенциал, прогноз, геоинформационные системы, слабоактивные регионы.

\section{Введение}

Сейсмическое районирование слабоактивных регионов проводится по разработанной в Горном институте УрО РАН методике, основанной на прогнозировании геодинамически неустойчивых зон и определении сейсмического потенциала региона. Нами разработана методика и определены принципы сейсмического районирования слабоактивных регионов. Использованы геологические и геофизические параметры для выделения геодинамически неустойчивых зон и построения прогнозных карт максимальных магнитуд возможных землетрясений $\left(M_{\max }\right)$. Достоверность прогнозных карт $M_{\max }$ основана на величине ошибки аппроксимации и на связи распределения сейсмического потенциала с тектоникой, геодинамикой и современной сейсмичностью. Применение методики в различных слабоактивных регионах и накопленный опыт позволили провести исследования по обобщению и определению роли базы данных в оценке сейсмического потенциала. Определена необходимая база данных для построения прогнозных карт $M_{\max }$ для небольших по площади регионов. Выявлены особенности базы данных для больших по площади и неоднородных в тектоническом отношении регионов, таких как восточная окраина Восточно-Европейской платформы и территория Соединенного Королевства Великобритании и Северной Ирландии. Для этих регионов необходимо создание расширенной базы данных и поиск дополнительных параметров, в результате применения которых можно получить наименьшие ошибки аппроксимации прогнозных карт $M_{\max }$. 


\section{Методика и подходы}

Определены основные методические аспекты сейсмического районирования слабоактивных регионов Западной и Восточной Европы, Урала и Западной Сибири (рис. 1).

Первым этапом является создание базы данных, которая включает геологогеофизические параметры и каталог тектонических землетрясений, произошедших с исторического периода по настоящее время [1].

В основу сейсмического районирования слабоактивных регионов положены принципы, которые опираются на представления об иерархичности структур сейсмичности и геофизической среды, масштабной однородности исходных геолого-геофизических данных, соответствии масштабов и иерархических порядков выделяемых зон, а также связи геолого-геофизических параметров с сейсмичностью. Этот принцип составляет основу предположения о том, что сходные по геолого-геофизическому строению зоны имеют близкие значения $M_{\max }$.

Определены связи сейсмичности с геолого-геофизическими параметрами базы данных регионов. Исследования проведены с помощью геоинформационной системы «ГЕО» в различных ее подсистемах; одни из них дают возможность определять значения поля в любой точке и строить разрезы по любому из направлений с учетом сейсмичности, другие позволяют определять графики функций, вошедших в прогноз [2, 3].

Следующим этапом разработанной методики является выделение геодинамически неустойчивых зон по комплексу геолого-геофизических данных исследуемых регионов [1].

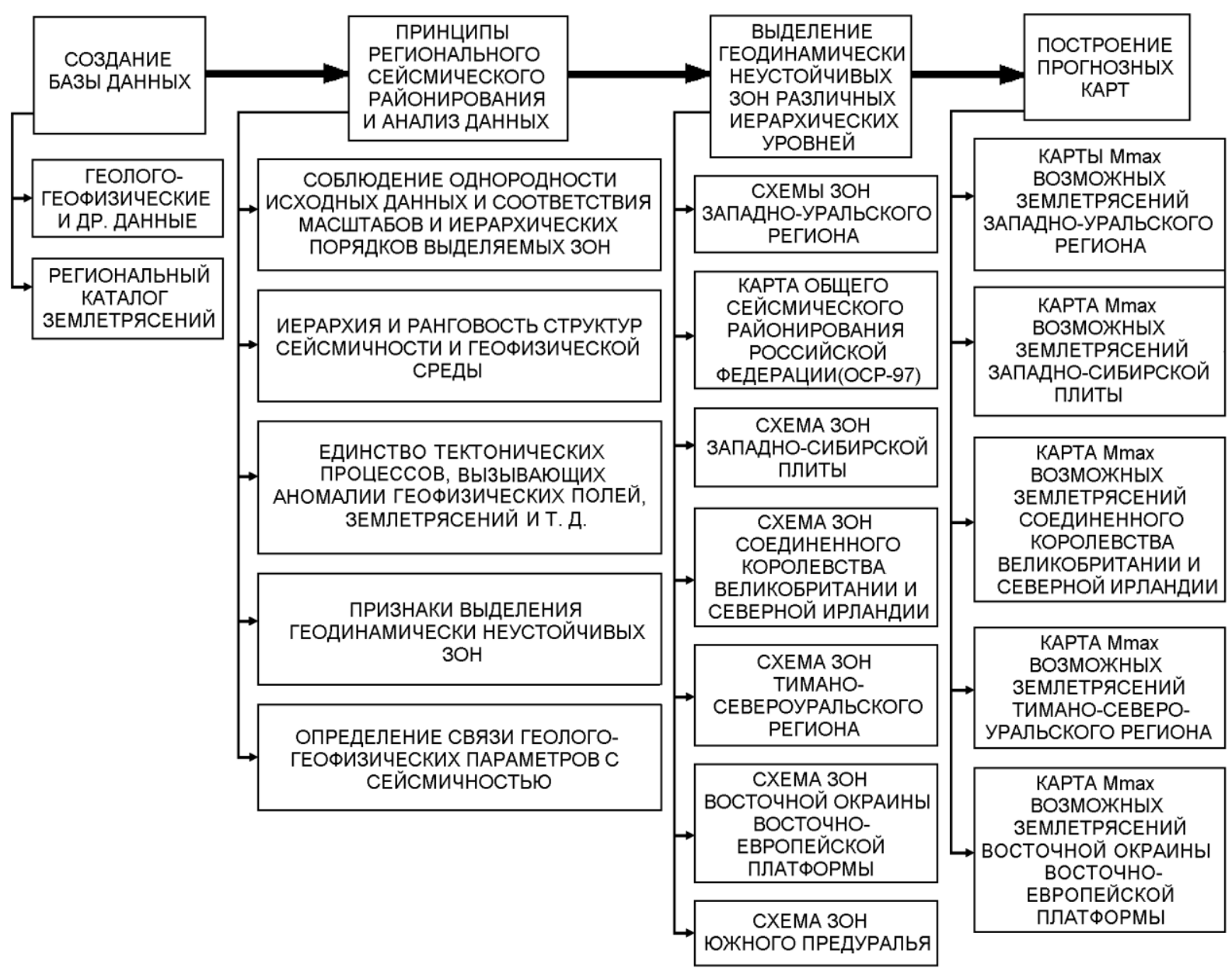

Рис. 1. Схема методики сейсмического районирования слабоактивных регионов 
Для расчета прогнозных карт максимальных магнитуд возможных землетрясений регионов была выбрана геоинформационная система «ГЕО» $[2,3]$. Информационные модели позволяют объединять всю доступную информацию об изучаемом явлении: описательное знание, экспертные гипотезы, методологию обработки, анализ разнотипных данных и знаний, а также получение прогнозных карт $M_{\max }[1,3]$. Автор системы В.Г. Гитис использовал для выделения зон сейсмичности и их оцифровки скопления землетрясений, что трудно сделать в слабоактивных регионах. По этой причине нами предложено использовать модели геодинамически неустойчивых зон. Основой для оцифровки является максимальная магнитуда землетрясений, которые попали в эти зоны. Внутри этих зон выбирались от 250 до 450 точек с помощью датчика случайных чисел, по ним создавали контрольную и учебную выборки, необходимые для нахождения прогнозирующей функции. Качество аппроксимации проверялось на контрольной выборке. Найденная функция $F(x, a)$ использовалась для прогноза $M_{\max }$ во всех остальных точках региона [2, 3].

Прогнозирующая функция в системе «ГЕО» ищется в виде:

$$
F(\boldsymbol{x}, \boldsymbol{a})=\sum_{i=1}^{I} \varphi_{i}\left(x_{i}, \boldsymbol{a}\right)
$$

где $\varphi_{i}\left(x_{i}, a\right)$ - кусочно-линейная функция от геолого-геофизического признака $x_{i}$, в которой узлы заранее заданы, а вектор оцениваемых параметров $a$ определяет значения функции в узлах.

Важным методическим вопросом является оценка точности аппроксимации значений $M_{\max }$ прогнозирующей функции $[2,3]$. Так как известные методы оценки точности аппроксимации требуют введения статистических предположений, которые не вытекают из реально решаемой задачи, в качестве формального показателя точности решения используется величина средней ошибки аппроксимации экспертных оценок $M_{\max }$. Сравнение средней ошибки аппроксимации для учебной и контрольной выборок позволяет проверить отсутствие «сверхподгонки» при оценивании параметров прогнозирующей функции.

Величина средней ошибки аппроксимации экспертных оценок не может служить единственным критерием правильности карты. Достоверность прогнозных карт максимальных магнитуд возможных землетрясений должна быть обоснована связью распределения сейсмического потенциала с тектоникой, геодинамикой и сейсмичностью регионов.

\section{Результаты и обсуждения}

В Горном институте УрО РАН созданы базы геологических, геофизических и геодезических данных для Тимано-Североуральского региона в сотрудничестве с Институтом геологии Коми НЦ УрО РАН $[1,4]$, для Соединенного Королевства Великобритании и Северной Ирландии совместно с Британской геологической службой $[1,6,8]$, для Западно-Уральского региона и восточной окраины Восточно-Европейской платформы [1]. В базы данных входит группа вещественных характеристик среды: характеристики магнитного поля, аномалии силы тяжести в редукции Буге, значения скоростей в различных толщах консолидированной коры и в земной коре в целом; группа структурных показателей вмещающей среды: градиенты потенциальных полей, глубина залегания поверхности кристаллического фундамента и границы Мохоровичича, мощности различных слоев консолидированной коры, плотность разломов; группа признаков, определяющих активность отдельных участков региона: неотектонические и современные вертикальные движения земной коры, характеристики рельефа и тепловые характеристики земной коры. Часть карт, составляющих базу данных, получена в геоинформационной системе «ГЕО» при помощи подсистемы генерирования знаний и фактов [3]. 
Обобщены параметры, используемые для построения прогнозных карт максимальных магнитуд возможных землетрясений исследуемых регионов. Это позволило определить различие базы данных для их расчета в зависимости от площади и тектонической неоднородности регионов.

\section{Прогнозные карты $M_{\max }$ Западно-Уральского}

\section{и Тимано-Североуральского регионов}

В каждом из вариантов прогнозных карт Западно-Уральского региона было использовано от 6 до 8 параметров, Тимано-Североуральского региона - 7 параметров [1]. Их обобщение показало, что база данных является стандартной для построения прогнозных карт $M_{\text {max }}$ с наименьшими средними ошибками аппроксимации для регионов с небольшой площадью. Она включает глубину залегания кристаллического фундамента и границы Мохоровичича, мощности нижнего, промежуточного и верхнего слоев консолидированной коры, рельеф земной поверхности, современные вертикальные движения земной коры, гравитационное поле, аномальное магнитное поле, тепловой поток и горизонтальные градиенты параметров, рассчитанные в системе «ГЕО». Для получения удовлетворительных средних ошибок аппроксимации прогнозных карт $M_{\max }$ рассматриваемых регионов не требуется больше никаких данных.

Прогнозные карты М и территории Соединенного Королевства Великобритании

\section{и Северной Ирландии}

Для данных регионов приходилось рассчитывать большое количество вариантов прогнозных карт максимальных магнитуд возможных землетрясений, чтобы получить достоверную карту. В каждом из вариантов прогнозных карт $M_{\max }$ для восточной окраины Восточно-Европейской платформы и территории Соединенного Королевства было использовано 7-8 параметров [1].

Проведено обобщение и получен список необходимых, а также дополнительных параметров для расчета прогнозных карт $M_{\max }$ с наименьшими средними ошибками аппроксимации для больших по площади и неоднородных в тектоническом отношении регионов. База данных содержит стандартный набор параметров, характерный для регионов с небольшой площадью, а также азимуты градиентов, максимальные и минимальные значения параметров, их разность и др. Это позволяет сделать геоинформационная система «ГЕО» $[2,3]$.

Для восточной окраины Восточно-Европейской платформы только после ввода в прогноз азимутов градиентов рельефа земной поверхности были получены удовлетворительные средние ошибки аппроксимации прогнозной карты $M_{\max }$. Для Соединенного Королевства использование дополнительного параметра, скоростей продольных волн на глубине 10,5 км, позволило получить прогнозную карту с удовлетворительными средними ошибками аппроксимации и подтвердить ее достоверность.

Существенный вклад в прогноз независимо от размера региона и его тектоники вносят функции от теплового потока, мощности различных слоев консолидированной коры и границы Мохоровичича. Совершенно неожиданным оказалось, что наибольший вклад в прогноз практически для всех вариантов прогнозных карт $M_{\max }$ вносит тепловой поток. Хотя это противоречит обычным представлениям о древних платформах, такой же результат был получен по данным корреляционного и факторного анализа на основе геолого-геофизической базы данных (более 20 параметров), имеющих отношение к современной структуре и глубинному строению Восточно-Европейской платформы. Оказалось, что в первый фактор с высоким весом входит тепловой поток [5]. Вероятно, либо до конца не изучен температурный режим платформы, либо данные о 
тепловом потоке содержат погрешности. Существенный вклад в прогноз глубины залегания границы Мохоровичича и мощности различных слоев консолидированной коры связан с тем, что геодинамически неустойчивые зоны имеют глубинный характер [7], они представляют собой модель, являющуюся основой построения прогнозных карт $M_{\max }$. На завершающем этапе определена достоверность прогнозных карт максимальных магнитуд возможных землетрясений [1]. Она обоснована связью распределения сейсмического потенциала с тектоникой, геодинамикой и сейсмичностью регионов.

\section{Выводы}

Рассмотрена методика сейсмического районирования слабоактивных регионов, основанная на выделении геодинамически неустойчивых зон и расчете сейсмического потенциала. Накопленный опыт построения прогнозных карт $M_{\max }$ позволил обобщить геологические и геофизические параметры различных вариантов прогноза. В небольших по площади регионах использование стандартной базы данных для построения прогнозных карт максимальных магнитуд возможных землетрясений не вызывает никаких затруднений. Особенность базы данных для построения таких карт для больших по площади и неоднородных в тектоническом отношении регионов состоит в расчете дополнительных параметров: азимутов градиентов, максимальных и минимальных значений параметров, их разности и др. Также необходимо использовать дополнительные параметры, которые позволяют расширить возможности построения прогнозных карт и получить их достоверные варианты.

Исследование выполнено при финансовой поддержке Программы ФНИ, проект № 0422-2019-0146-С-02 (регистрачионный номер темы НИОКТР: AAAA-A18-118040690028-5).

\section{БИБЛИОГРАФИЧЕСКИЙ СПИСОК}

1. Блинова Т.С., Удоратин В.В., Дягилев Р.А., Баранов Ю.В., Носкова Н.Н., Конанова Н.В. Сейсмичность и сейсмическое районирование слабоактивных территорий / ГИ УрО РАН [и др.]. - Пермь, 2015. - $178 \mathrm{c}$.

2. Гитис В.Г., Деарт Д.А., Ошер Б.В., Руденко С.Л. ГЕО - Экспертная система для геологогеофизического прогноза // Экспертные система: состояние и перспективы: сб. науч. тр. - М., 1989. C. 119-130.

3. Гитис В.Г., Ермаков Б.В. Основы пространственно-временного прогнозирования в геоинформатике [электронный ресурс]. - М.: Физматлит, 2004. - 256 с.

4. Литосфера Тимано-Североуральского региона: геологическое строение, вещество, геодинамика / отв. ред.: А.М. Пыстин, А.И. Антошкина, Л.В. Махлаев; РАН, УрО, Коми НЦ. - Сыктывкар: Геопринт, 2008. $-235 \mathrm{c}$.

5. Николаев В.А. Карта геодинамического районирования Восточно-Европейской платформы для новейшего тектонического этапа // Современная геодинамика, глубинное строение и сейсмичность платформенных территорий и сопредельных регионов: материалы Междунар. конф. / Воронеж. Гос. Ун-т. - Воронеж, 2001. - C. 149-151.

6. Blinova T., Evans R., Booth D., Semerikova I., Baranov Y. Seismic potential of the United Kingdom // International Multidisciplinary Scientific GeoConference Surveying Geology and Mining Ecology Management, SGEM: Proceedings of 15th International Multidisciplinary Scientific Geoconference and EXPO, SGEM 2015. - Albena, Bulgaria, 2015. - V. III. - P. 971-982. - DOI: 10.5593/sgem2015B13.

7. Blinova T. Generalization of the features of the geodynamically unstable zones and their connection with the deep structure low seismic activity regions // International Multidisciplinary Scientific GeoConference Surveying Geology and Mining Ecology Management, SGEM: $19^{\text {th }}$ SGEM 2019, Bulgaria, 30 june-6 july. Albena, 2019. - V. 19, № 1.1. - P. 813-820. - DOI: 10.5593/sgem2019/1.1.

8. British Geological Survey: сайт. - Текст электронный. - URL: http://www.bgs.ac.uk /home.html. (Дата обращения 23.03.2021). 